\title{
Fuel property and fuel temperature effects on internal nozzle flow, atomization and cyclic spray fluctuations of a direct injection spark ignition-injector
}

International J of Engine Research

14(6) 543-556

(c) IMechE 2013

Reprints and permissions:

sagepub.co.uk/journalsPermissions.nav DOI: $10.1177 / 1468087413482320$ jer.sagepub.com

@SAGE

\author{
Lars Zigan $^{1,2}$, Jun-Mei Shi ${ }^{3}$, Ivan Krotow ${ }^{3}$, Ingo Schmitz ${ }^{1,2,4}$, \\ Michael Wensing ${ }^{1,2}$ and Alfred Leipertz ${ }^{1,2}$
}

\begin{abstract}
The effect of fuel properties and fuel temperature on the behaviour of the internal nozzle flow, atomization and cyclic spray fluctuations is examined for a three-hole direct injection spark ignition injector by combining numerical simulation of the nozzle flow with macroscopic and microscopic spray visualization techniques. A dominant influence of the liquid fuel viscosity on the highly unsteady, cavitating nozzle flow and spray formation was observed. A reduced viscosity (or larger Reynolds number) increases the flow velocity, turbulence and cavitation in the nozzle and leads to a slim spray with a reduced width but increased spray penetration. Furthermore, the spray cone angle is larger for lower Reynolds numbers due to the changed internal nozzle flow profile as predicted by the numerical calculation. The shot-to-shot fluctuations of the sprays were found to have their origin in the highly unsteady, cavitating nozzle flow. Larger cyclic spray fluctuations were observed at low Reynolds numbers although the predicted vapour formation in the nozzle is weaker. This can be explained by flow instabilities at low Reynolds numbers leading to large fluctuations in the nozzle flow.
\end{abstract}

\section{Keywords}

Direct injection spark ignition, cavitation, fuel effects, cyclic spray variations, needle lift

Date received: 28 May 2012; accepted: 19 February 2013

\section{Introduction}

Direct injection spark ignition (DISI) internal combustion (IC) engines provide a promising technology to minimize fuel consumption and pollutant emissions. Especially, turbocharging and downsizing show not only a high potential but also complexity in spray control and mixture homogenization. There is a need of optimizing injection, ignition and combustion strategies to ensure an overall homogenized air-fuel mixture in the engine avoiding wall impingement. Detailed knowledge is required for precise control of atomization, spray geometry and spray propagation under various operating conditions. Today multi-hole nozzles are mainly used for the DISI fuel injectors ${ }^{1,2}$ because of their simplicity, robustness and cost-effectiveness. Further injector types are available such as piezoactuated outwardly opening pintle nozzles that are much more cost-intensive but show advantages in generating a very fine and reproducible spray $^{3,4}$ for a fast mixture formation. This is currently of great interest for reduction of soot formation during mixing-controlled combustion. For optimization of those injectors and sprays, an enhanced understanding of the complex fluid dynamics inside the nozzle is required including turbulence, cavitation and large-scale vortices that determine the jet atomization.

\footnotetext{
'Lehrstuhl für Technische Thermodynamik (LTT), Universität ErlangenNürnberg, Erlangen, Germany

${ }^{2}$ Erlangen Graduate School in Advanced Optical Technologies (SAOT), Universität Erlangen-Nürnberg, Erlangen, Germany

${ }^{3}$ Continental Automotive GmbH, Regensburg, Germany

${ }^{4}$ Lehrstuhl für Technische Thermodynamik (TTS), Universität Siegen,

Siegen, Germany
}

\section{Corresponding author:}

Lars Zigan, Lehrstuhl für Technische Thermodynamik (LTT), Universität Erlangen-Nürnberg, Am Weichselgarten 8, D-91058 Erlangen, Germany. Email: lars.zigan@cbi.uni-erlangen.de 
Another challenge is the application of modern biofuel and synthetic fractions mixed with fossil fuel components changing the nozzle flow, atomization and evaporation behaviour. The different fuel properties might change the spray and combustion processes that can hardly be predicted by semi-empirical models that require experimental data for validation of numerical results. The development of reliable break-up models is important for understanding the influence of internal nozzle flows on the liquid disintegration process and for predicting the performances of several mixing devices and combustion systems. ${ }^{5}$

Many empirical atomization models exist in the literature and are applied in spray simulation codes, taking into account mainly aerodynamic effects but some of them also turbulence- or cavitation-induced break-up. ${ }^{6}$ Classical atomization approaches such as the 'wave' model $^{7}$ are purely based on aerodynamic-induced break-up, and the influence of the inner nozzle flow on jet atomization cannot be predicted. ${ }^{8}$ The break-up is driven by Kelvin-Helmholtz (KH) instabilities leading to surface wave growth and droplet detachment, see Figure 1(a). This process is relatively well understood and implemented in computational fluid dynamics (CFD) and widely applied. The few existing direct numerical simulation (DNS)-like calculations of the jet disintegration mainly treat this break-up mechanism. ${ }^{9}$

Furthermore, turbulent fluctuations in the nozzle flow may be responsible for initial jet surface disturbances, ${ }^{10}$ see Figure 1(b). Those turbulence-induced surface waves grow due to the above-mentioned $\mathrm{KH}$ instabilities leading to jet disintegration (turbulenceinduced break-up). Especially, in high-speed diesel nozzle flows, two-phase regions are generated due to cavitation. ${ }^{11-14}$ Well-known is the geometric cavitation appearing at the inlet of the injection hole mainly in flow recirculation zones, where the local pressure drops

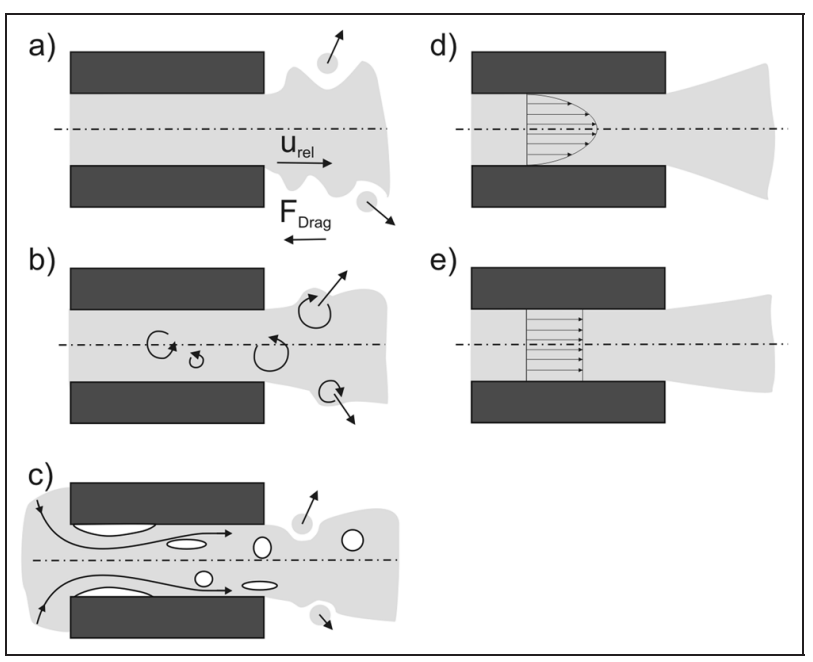

Figure I. Schematic of jet disintegration mechanisms: (a) aerodynamic-induced, (b) turbulence-induced, (c) cavitationinduced and (d, e) flow-induced break-up. below the vapour pressure, see Figure 1(c). The collapse of cavitation bubbles at the nozzle exit induces strong turbulence that supports ligament formation (cavitation-induced break-up).

Additionally, when changing the injection pressure, or the fuel and, therefore, its respective viscosity, the flow regime (Reynolds number) could be altered significantly. Especially, the near-nozzle cone angle may be influenced by the flow profile. A fully developed turbulent flow (Figure 1(e)) leads to a more homogeneous velocity profile at the nozzle exit compared to the laminar flow (Figure 1(d)), which should be visible in the cone angle of the jet inversely scaling with the Reynolds number (flow-induced break-up). However, there is always an interference with the shear flow of the ambient resting air and additional interaction of aerodynamic- or cavitation-induced break-up.

Current CFD calculations mainly treat either pure nozzle flow or just spray formation. The reason is the high numerical effort and the complex coupling of the turbulent two-phase internal nozzle flow and the external nozzle spray formation. ${ }^{8}$ Some nozzle flow phenomena such as hydraulic flip ${ }^{15}$ and gas re-entrance regions near the nozzle exit cannot be captured by the separation of interior and exterior nozzle regions. Additionally, transient effects such as turbulence, vortex dynamics and super-cavitation are severely dampened. ${ }^{16}$

Some nozzle flow effects were included in current empirical atomization models ${ }^{11,14}$ to predict their influence on the initial jet angle. For example, in the study by Baumgarten, ${ }^{11}$ the turbulence- and cavitation-based primary break-up model has been combined with the $\mathrm{KH}$ model for the secondary break-up. Most of the cavitation-related studies were focused on high-pressure diesel injection, and there are only few data available for DISI atomization, which appears completely different $^{17}$ due to lower injection pressure, different nozzle geometry $(\mathrm{L} / \mathrm{D}$, mini sac hole) and needle form.

A special task is the identification and minimization of cyclic spray fluctuations especially for spray-guided DISI concepts. The work of Andriotis et al. ${ }^{18}$ focused on string cavitation (vortex-type cavitation), which, in contrast to geometrical cavitation, strongly supports spray instabilities like cycle-to-cycle variations. Those vapour structures are usually found in the bulk of the liquid fuel in the region where vortical flow structures exist. ${ }^{19}$ The formation of the vapour volume fraction at a certain location is very irregular, and their interaction with the mean flow is poorly understood. Its presence in the injection hole leads to an increase of the spray cone angle at the side of its occurrence related to the hole axis. ${ }^{18}$

Additionally, in literature the research on the effect of fuel properties on the nozzle flow and atomization is still insufficient, especially for gasoline direct injection. Only a few fundamental studies using real-size transparent nozzles, ${ }^{20}$ simple throttle or model nozzle geometries are published. ${ }^{19}$ For example, in a numerical study, the influence of different fuels and fuel 
temperatures on generic nozzle flow and geometricand vortex-induced cavitation behaviour was investigated. ${ }^{19}$ The fuel viscosity was reported to be the most significant influencing parameter, and the effects of the vapour pressure play a minor role in flows where the fuel temperature is well below the vaporization temperature. This is due to the large pressure gradients in the nozzle. The density and the surface tension of the fuel showed only a minor influence on the flow if the other parameters were kept constant; however, they cannot be neglected. Nevertheless, it is unknown whether those conclusions are valid for flows in realsize multi-hole nozzles because of the higher complexity of cavitation and turbulent flow.

In the study by Park et al., ${ }^{21}$ the characteristics of diesel fuel and biodiesel for turbulent flow, cavitating flow and hydraulic flip were investigated for transparent large-scale nozzles. For this investigation, the important non-dimensional numbers are the liquid Reynolds number

$$
\operatorname{Re}=\frac{d_{0} U_{l}}{\nu_{l}}
$$

the liquid Weber number

$$
\mathrm{We}=\frac{\rho_{l} d_{0} U_{l}^{2}}{\sigma}
$$

and the cavitation number

$$
\mathrm{CN}=\frac{p-p_{v}}{\rho / 2 U_{l}^{2}}
$$

The included properties are the liquid fuel density $\rho_{l}$, the kinematic viscosity $\nu_{l}$ and the surface tension $\sigma$ as well as the velocity of the liquid phase $U_{l}$, the nozzle bore diameter $d_{0}$ and the fuel vapour pressure $p_{v}$.

For the stationary flow, the geometrical cavitation and hydraulic flip occur at constant Weber numbers for both diesel and biodiesel, but for biodiesel, it starts already at much smaller Reynolds numbers. ${ }^{21}$ The cavitation patterns at the nozzle orifice wall were very similar. No effect of fuel properties on the resulting spray geometry was reported.

Sou et al. ${ }^{15}$ investigated the influence of Reynolds numbers $(\mathrm{Re}=45,000-76,000)$ and cavitation numbers $(\mathrm{CN}=0.55-1.57)$ on formation of cavitation zones in the nozzle and the resulting liquid jet by varying the nozzle size, fluid properties and liquid flow rate. The geometric-induced cavitation zones and the shape of the liquid jet at the nozzle exit are not strongly affected by the Reynolds number but by the cavitation number. $^{15}$ At geometric cavitation conditions, the spray cone angle increases with smaller surface tension (of light oil compared to water). An increase of the fluid temperature also leads to larger spray plume angle for water. $^{15}$

In the study by Zigan et al., ${ }^{2,22}$ the atomization quality of a 12-hole injector at $1.5 \mathrm{MPa}$ ambient pressure was found to be different for high-viscosity fuels that show optically thinner sprays with a smaller average droplet size, especially for short injection durations. The n-decane droplets showed a larger droplet momentum and a stronger fuel-air interaction with marginally increased radial spray propagation. These complex phenomena are explained by the viscosity-dependent turbulent, cavitating nozzle flow and can hardly be predicted by classical atomization models, ${ }^{23}$ which are purely based on aerodynamic break-up effects

$$
d_{32} \propto d_{0}^{0,5} \cdot \Delta p^{-0,5} \cdot \sigma^{-0,25} \cdot \rho_{g}^{-0,25} \cdot \mu_{L}
$$

This indicates an increase of the droplet size $d_{32}$ proportional to the fuel viscosity $\mu_{L}$, which is mainly due to aerodynamic break-up. Atomization is promoted by low fuel viscosity without considering nozzle flow effects, which is justified at high injection pressure with high relative velocity and dominant aerodynamic break-up. Here, $\Delta p$ is the pressure difference between injection pressure and ambient pressure and $\rho_{g}$ is the gas density.

Especially, at DISI conditions with lower injection pressure, the nozzle flow effects may be predominant, and especially for this injection regime, further investigation of the fuel-dependent atomization behaviour is necessary.

In this study, first, results regarding fuel properties and fuel temperature effects on nozzle flow as well as macroscopic and microscopic spray behaviour are presented for a three-hole nozzle. It is focused on the detailed analysis of the fuel-dependent cavitation behaviour that is presented in the form of a numerical study. The resulting microscopic spray structure is analysed with locally high-resolved Mie scattering imaging at injector opening and full needle lift. This article is subdivided into two parts: in the first section, a brief description of the experimental and numerical setup is presented. The second section gives an overview of fuel property and fuel temperature effects on the nozzle flow and atomization and describes the effects of part and full needle lift.

\section{Materials and methods}

Two single-component fuels (n-hexane and n-decane) with large differences in viscosity, surface tension and volatility were studied. These fuels are capable to cover the gasoline fuel properties in a wide range. Additionally, the fuel properties were varied by changing the fuel temperature (either $25^{\circ} \mathrm{C}$ or $70^{\circ} \mathrm{C}$ ) to influence the atomization process. Fuel and injector were conditioned to the same temperature. The resulting Reynolds and liquid Weber numbers, see equations (1) and (2), are in the range of $\mathrm{Re}=9400-39,600$ and $\mathrm{We}=19,200-44,500$, respectively, see Table 1 . The Reynolds and Weber numbers are calculated from the fuel velocity during needle opening. The spray experiments were conducted in an optical accessible injection chamber. The injection pressure was set to $10 \mathrm{MPa}$ with 
Table I. Fluid properties ${ }^{24,25}$ and non-dimensional numbers of atomization.

\begin{tabular}{lllll}
\hline & n-decane $\left(25^{\circ} \mathrm{C}\right)$ & n-decane $\left(70^{\circ} \mathrm{C}\right)$ & n-hexane $\left(25^{\circ} \mathrm{C}\right)$ & n-hexane $\left(70^{\circ} \mathrm{C}\right)$ \\
\hline Density $\left(\mathrm{kg} / \mathrm{m}^{3}\right)^{34}$ & 717 & 689 & 656 & 618 \\
Kinetic viscosity $\times 10^{-6}\left(\mathrm{~m}^{2} / \mathrm{s}\right)^{24}$ & 1.223 & 0.765 & 0.446 & 0.339 \\
Vapour pressure $(\mathrm{kPa})^{34}$ & 0.2 & 1.9 & 19.9 & 88.9 \\
Surface tension $(\mathrm{mN} / \mathrm{m})^{25}$ & 23.0 & 19.0 & 18.0 & 13.0 \\
Reynolds number & 9360 & 19,814 & 28,482 & 39,585 \\
Weber number & 19,232 & 32,920 & 29,349 & 44,453 \\
\hline
\end{tabular}

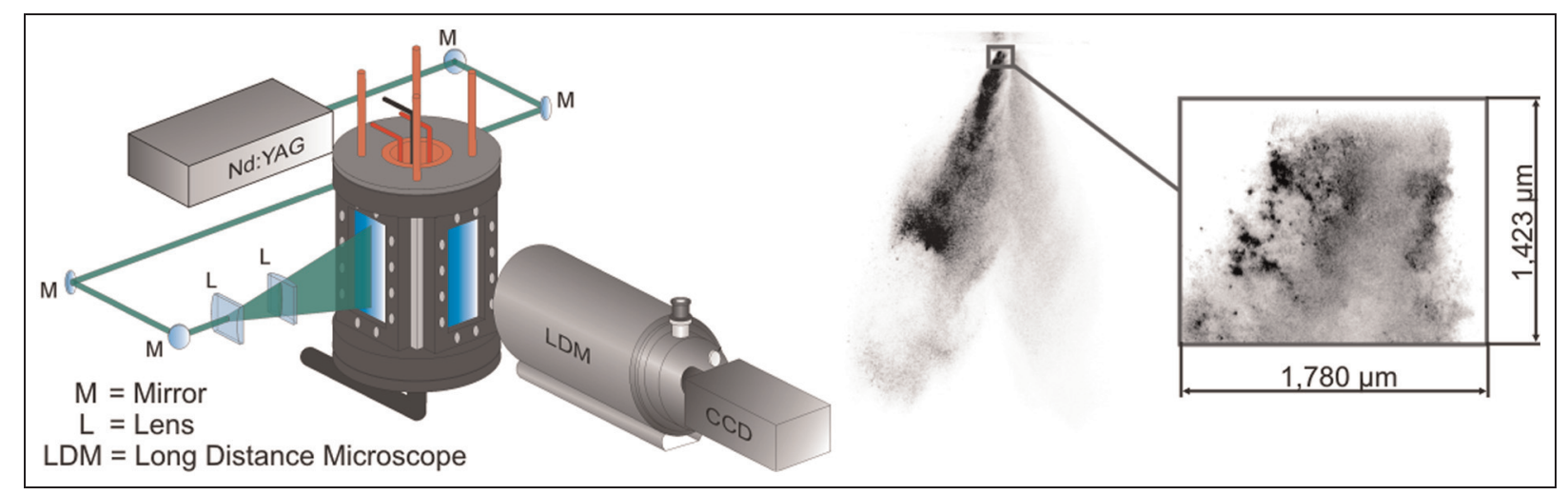

Figure 2. Experimental setup to investigate the spray structure (left), macroscopic laser light sheet illumination of one jet (centre) and detection of the microscopic spray I mm below the nozzle orifice (right).

a flexible fuel system. A constant air flow (flow velocity $<0.1 \mathrm{~m} / \mathrm{s}, \vartheta_{\text {Air }}=25^{\circ} \mathrm{C}$ ) through the injection chamber scavenges it from one injection to another. The injection repetition rate was set to $1 \mathrm{~Hz}$. The investigated research injector is based on a six-hole solenoid injector (Continental XL2); the nozzle, however, was equipped with a three-hole plate for better optical access to the single fuel jets.

The spray process was examined using laser-based macroscopic and microscopic planar Mie scattering imaging techniques, see Figure 2. The left jet in Figure 2 (right image) is illuminated with a thin laser light sheet for both macroscopic and microscopic spray visualization. With the application of a long-distance microscope, the jet disintegration close to the nozzle orifice was studied in detail in a region of approximately $1.8 \times 1.4 \mathrm{~mm}$. The thickness of the investigated spray volume is limited in depth by the laser light sheet (thickness is $<500 \mu \mathrm{m}$ ) and especially by the focal depth of the optics $(80 \mu \mathrm{m})$. In the studies by Badock et al., ${ }^{13}$ Fath et al., ${ }^{26}$ Heimgärtner and Leipertz ${ }^{27}$ and Schmitz et al., ${ }^{28}$ the capability of this technique is shown for the identification of microscopic spray structures such as ligaments, clusters, cavities and liquid core. Limitations are unpredictable scattering properties due to multiple scattering at the rough stochastic interface of the spray, which might cause a milky haze in front of the observed plane. This disturbing scattered light makes the optical access of the inner spray structures difficult. Nevertheless, geometric spray quantities like microscopic spray cone angle, spray width and spray bending can be analysed with this technique.
The injector shows a characteristic unsteady, turbulent flow behaviour also for low injection pressures due to vortex shedding at the needle tip (for more details, see Shi et al. $\left.{ }^{29}\right)$. The injection duration was kept constant for all investigated fuels at $1000 \mu$ s resulting in an injected mass of approximately $9 \mathrm{mg} /$ pulse (gravimetric measurement, averaged over $3 \times 1000$ injections). The bore diameter of the nozzle holes is approximately $250 \mu \mathrm{m}$.

The CFD calculations were performed with the commercial CFD solver ANSYS-CFX 12.1. To describe the two-phase flow, a homogeneous two-fluid model is used. With this, the liquid and gaseous phases are considered as a homogeneous mixture sharing the velocity and pressure fields. The transient flow is described by an unsteady Reynolds-averaged NavierStokes (URANS) approach by using the k-omega shear stress transport (SST) turbulence model. ${ }^{30}$ The cavitation was accounted by a Rayleigh-Plesset equation ${ }^{31}$ based model. The Reynolds-averaged Navier-Stokes equations of the whole mixture consisting of liquid and vapour phases can be described by

$$
\frac{\partial \rho_{v} \alpha}{\partial t}+\frac{\partial \rho_{v} \alpha U_{i}}{\partial x_{i}}=S_{l v}
$$

and

$$
\begin{aligned}
& \frac{\partial \rho_{m} U_{i}}{\partial t}+\frac{\partial \rho_{m} U_{i} U_{j}}{\partial x_{j}}=-\frac{\partial p}{\partial x_{i}}+\frac{\partial \tau_{i j}}{\partial x_{j}} \text { with } \\
& \tau_{i j}=\left(\mu_{m}+\mu_{m t}\right)\left(\frac{\partial U_{i}}{\partial x_{j}}+\frac{\partial U_{j}}{\partial x_{i}}\right)
\end{aligned}
$$




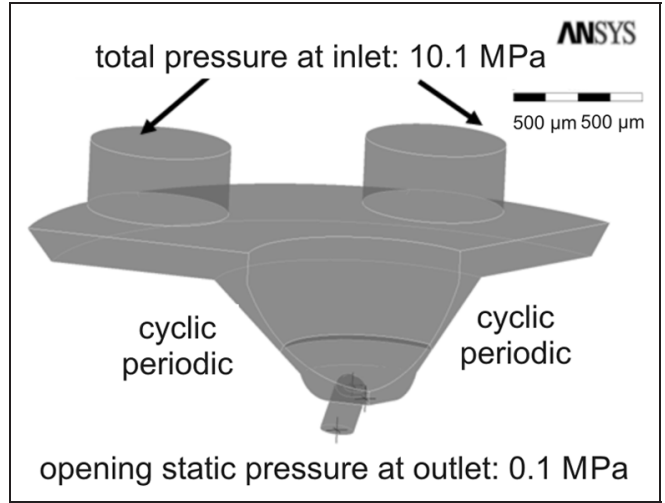

Figure 3. Computational domain of the nozzle.

$U_{i}$ and $U_{j}$ represent the averaged velocity components (with $i, j=1, \ldots, 3$ ), $\alpha$ is the vapour volume fraction and $\rho_{v}$ and $\rho_{l}$ are the vapour and liquid density, respectively. From this, the value of the liquid volume fraction $(1-\alpha)$ can be calculated. Then, the average mixture density $\rho_{m}$ is calculated from the mass fraction of liquid and vapour phases in the respective cell

$$
\rho_{m}=\alpha \rho_{v}+(1-\alpha) \rho_{l}
$$

In equation (6), $\mu_{m}$ is the dynamic molecular viscosity of the mixture and $\mu_{m t}$ is the turbulent viscosity that is solved by the turbulence model. $S_{l v}$ represents the source/sink term of the mass during phase change due to cavitation. If the local pressure $p$ drops below the vapour pressure $p_{v}$, a part of the liquid mass is converted into the vapour phase (cavitation). Vapour condensation occurs if the local pressure is higher than the vapour pressure. Applying the Rayleigh-Plesset equation $^{31}$ leads to the following calculation model for cavitation-induced mass transport at phase change

$$
S_{l v}= \begin{cases}\operatorname{sign}\left(p_{v}-p\right) F_{1} \frac{3 \alpha_{0}(1-\alpha) \rho_{v}}{R_{b}} \sqrt{\frac{2}{3} \frac{p_{v}-p}{\rho_{l}}} & \text { if } p<p_{v} \\ \operatorname{sign}\left(p_{v}-p\right) F_{2} \frac{3 \alpha \rho_{v}}{R_{b}} \sqrt{\frac{2}{3} \frac{p-p_{v}}{\rho_{l}}} & \text { if } p>p_{v}\end{cases}
$$

where $\operatorname{sign}\left(p_{v}-p\right)$ indicates the direction of the mass transfer, $\alpha_{0}$ represents the volume fraction of the cavitation nuclei in the fluid, $R_{b}$ is the average bubble radius and $F_{1}$ and $F_{2}$ are the evaporation and condensation coefficients introduced to account for different bubble expanding and shrinking velocities depending on the respective fluid and boundary conditions. In order to understand the link between nozzle flow and atomization, the turbulence energy $T_{k e}$ and the kinetic energy of flow motion in the axial direction of injection hole and in the non-axial directions $E_{k}$ at the nozzle exit were monitored for each numerical time step. These quantities are evaluation parameters of the numerical study related to the respective cell. The turbulent kinetic energy is defined by

$$
T_{k e}=\frac{1}{2}\left(u_{1}^{\prime 2}+u_{2}^{\prime 2}+u_{3}^{\prime 2}\right)
$$

including the fluctuations of the velocities $u_{1}^{\prime}, u_{2}^{\prime}$ and $u_{3}^{\prime}$ in the three spatial directions $x, y$ and $z$. For the definition of non-axial motion (e.g. swirling vortex in the injection hole), the non-axial kinetic energy $E_{k}$ is applied. This is generated by the deflection of the nozzle flow and determines the atomization efficiency. There, the non-axial flow velocities $u_{1}$ and $u_{2}$ in $x$ - or $y$ direction are included, that is, both radial and tangential velocity components

$$
E_{k}=\frac{1}{2} \rho_{L}\left(u_{1}^{2}+u_{2}^{2}\right)
$$

These quantities were defined as local variables, and mass flow rate weighted averages were calculated over the nozzle orifice exit plane. Standard deviations were calculated from the temporal profile for the nozzle outlet area to quantify the cyclic variations.

The computational domain is shown in Figure 3. The nozzle is axis-symmetrical with three injection holes. A $120^{\circ}$-sector geometrical model was adopted, and a cyclic period condition was applied at the sector boundaries. A static pressure outlet condition allowing entrainment was defined at the hole exit and zero gradient condition for other quantities. The second-order discretization scheme in both space and time was used. The temporal resolution is $0.2 \mu \mathrm{s}$. The computation grid is sufficiently fine with less than $1 \mu \mathrm{m}$ near the wall and most of $\mathrm{y}+$ is less than 2. Usually, more than 15 nodes are inside the boundary layer.

\section{Results and discussion}

In general, the investigated three-hole injector shows a highly unsteady spray behaviour with strong cyclic spray variations for the fuel n-decane, see Figures 4 and 5. In Figure 4, single images of the integral spray are shown that are illuminated with flash lamps. The time values are based on the visible start of injection (vSOI). In general, each single jet shows pulsations in axial direction. This reflects the flow dynamics of the nozzle

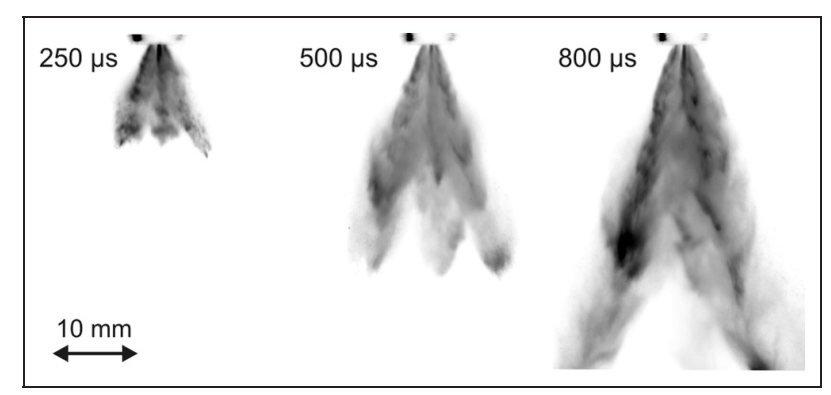

Figure 4. Global spray structure of the investigated three-hole injector (integral Mie scattering, flash-lamp illumination, singleshot images). 


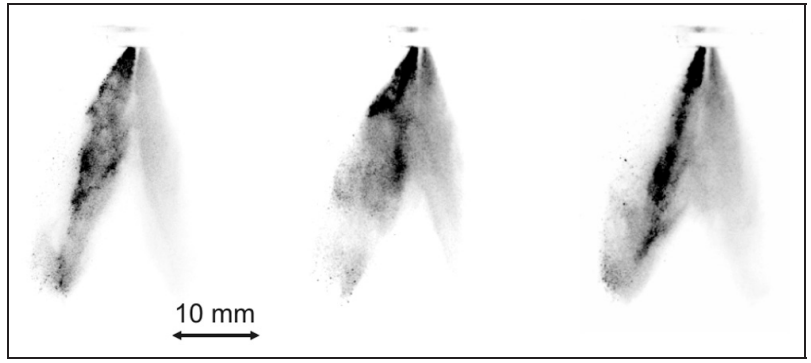

Figure 5. Exemplary images of one illuminated jet of the spray showing the macroscopic spray fluctuations as well as the jet-tojet interactions between the single jets, $\mathrm{n}$-decane, $p_{\text {inj }}=10 \mathrm{MPa}$, $\vartheta_{\text {Fuel }}=25^{\circ} \mathrm{C}, t=500 \mu \mathrm{s}$ after vSOI.

internal flow due to vortex shedding ${ }^{29}$ and cavitation vapour shedding at the needle. In Figure 5, exemplary single-shot planar Mie scattering images are presented additionally showing strong cyclic variations of the single jet width and injection direction (i.e. bent angle), which promote jet-to-jet interactions.

The fuel properties are expected to significantly influence the nozzle flow and, thus, should affect the atomization and spray shape as well as cyclic spray fluctuations. In Figure 6, the fuel effect on the macroscopic spray propagation is shown. The occurrence frequency is used to describe the cyclic fluctuations of the liquid phase of the spray from shot-to-shot. The occurrence frequency is calculated from 32 single-shot images. For the computer post-processing of the single images, a threshold was defined to $10 / 255$ for the 8-bit converted images to distinguish between liquid fuel $(>10)$ and image background ( $<10$, low scattering intensity). The threshold value is chosen in a way to include also spray regions with low liquid concentration and, therefore, low scattering light intensity. The width of the zone with occurrence frequencies between $0 \%$ (no detected scattering signal in the respective pixel in 32 images) and $100 \%$ (high scattering intensity in all images) represents the cyclic variability of the spray shape. If this zone is thin, the spray shows less cyclic variations indicating a high reproducibility. For n-decane at $25^{\circ} \mathrm{C}$, large cyclic fluctuations are visible. These cyclic variations are damped for larger Reynolds numbers, that is, the n-hexane spray with increased fuel temperature shows the highest reproducibility. Especially, nozzle flow instabilities at very low Reynolds numbers ${ }^{17}$ seem to support the large cyclic fluctuations of the spray for $\mathrm{n}$-decane, which is visible in the large range of the jet cone angle.

Furthermore, for some injections the spray width is increased for $\mathrm{n}$-decane leading to a more intense fuelair interaction enhancing the jet break-up, and therefore, a reduced spray penetration results. An increased fuel temperature leads to a reduced macroscopic spray width and the spray propagates further downstream. This can be explained by the reduced fuel viscosity leading to a larger injection velocity. Additionally, the nhexane spray at $70^{\circ} \mathrm{C}$ fuel temperature is further bent towards the injector axis; therefore, the spray shows a reduced radial expansion and a larger spray length.

The microscopic spray structure analysis conducted close to the nozzle shows similar trends, see Figures 79. Large cyclic fluctuations in the spray shape occur for n-decane during the opening phase of the needle (at $200 \mu \mathrm{s})$, see Figure 7(a). The Reynolds number under this condition is relatively low (see Table 1). After the needle is fully lifted (quasi-stationary injection phase, e.g. at $500 \mu \mathrm{s}$, Figure 7(b)), the cyclic variations are reduced due to the pressure and velocity rise. This means that the Reynolds number rises leading to a more stable nozzle flow and spray behaviour. However, the Reynolds number is still relatively small and the injection is in the transitional low turbulent flow regime.

In Figure 8, single-shot images of n-hexane are presented that show smaller cyclic fluctuations compared to n-decane confirming the Reynolds number dependency of the flow and atomization. The microscopic spray flipping is further reduced at increased fuel temperature as illustrated in Figure 9 by the occurrence frequency of liquid fuel (the threshold to separate between spray and background is $15 / 255$ for the microscopic images). It becomes apparent that the microscopic

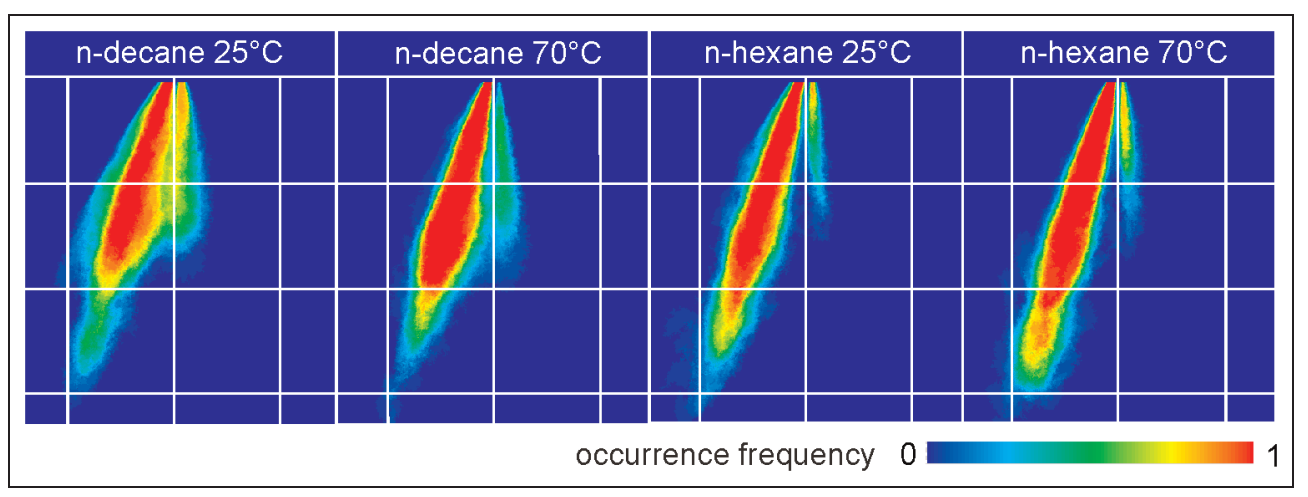

Figure 6. Occurrence frequency distribution indicating the cyclic fluctuations of the macroscopic spray, calculated from 32 singleshot images. Grid: $10 \mathrm{~mm}$, time: $800 \mu \mathrm{s}$. 


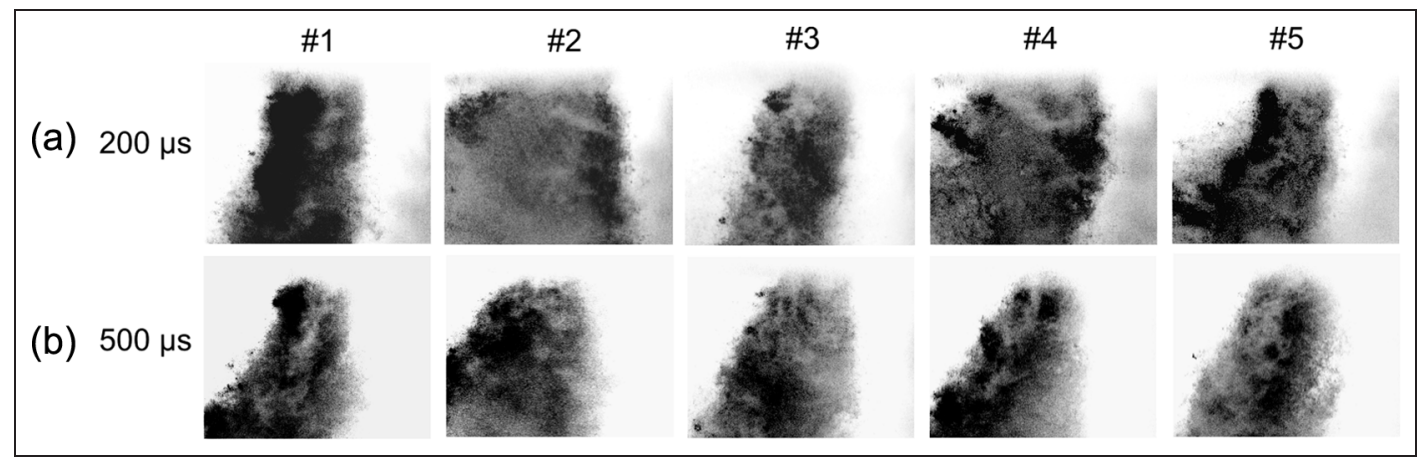

Figure 7. Exemplary single-shot images of the microscopic spray for $n$-decane during (a) needle opening (200 $\mu$ s) and (b) the quasistationary injection phase $(500 \mu \mathrm{s}), \vartheta_{\text {Fuel }}=25^{\circ} \mathrm{C}$.

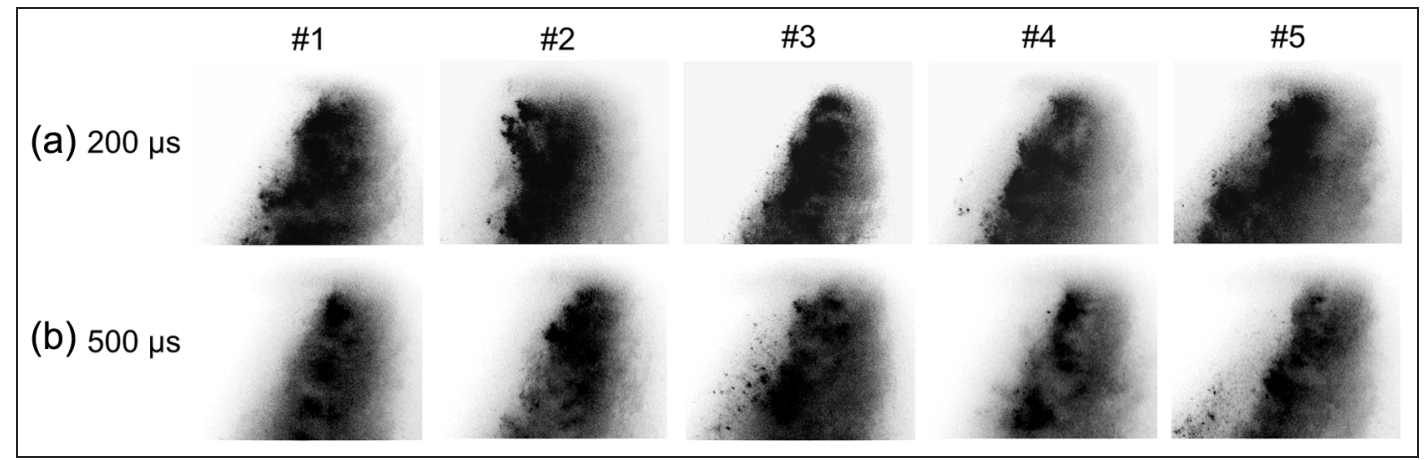

Figure 8. Exemplary single-shot images showing the cyclic fluctuations of the near-nozzle, microscopic spray for n-hexane and during (a) early injection phase $(200 \mu \mathrm{s})$ and (b) quasi-stationary injection phase $(500 \mu \mathrm{s}), \vartheta_{\text {Fuel }}=25^{\circ} \mathrm{C}$.

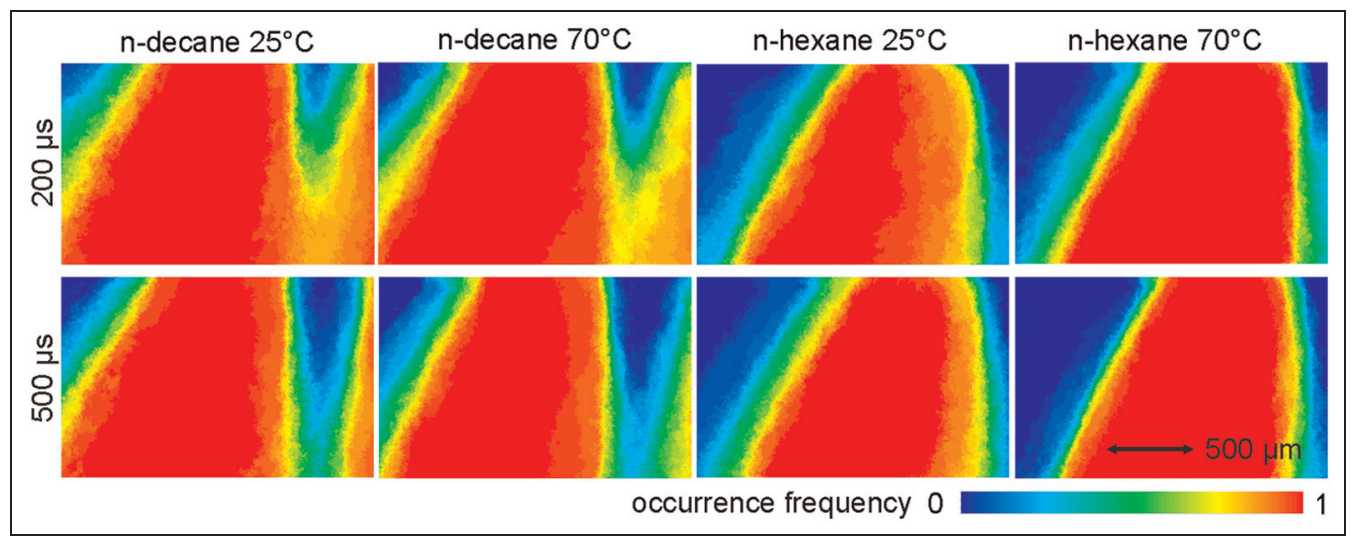

Figure 9. Occurrence frequency of liquid fuel distribution showing the spray shape and the cyclic fluctuations of the microscopic spray for two fuel temperatures $\left(\vartheta_{\text {Fuel }}=25^{\circ} \mathrm{C} / 70^{\circ} \mathrm{C}\right)$ and two times $(200$ and $500 \mu$ s after vSOI).

spray of n-decane shows large fluctuations in the spray width and the spray cone angle, especially during injector opening, which is indicated by the broad yellowgreen zone. For n-decane, the larger jet-flipping is clearly visible, leading to jet-to-jet interactions further downstream in the spray (see Figure 5). During the quasi-stationary phase, this spray flipping is reduced especially for n-hexane at elevated fuel temperature. The spray is very reproducible, which is displayed by the sharp edge at the spray boundary of the occurrence frequency distribution. The reduction of the spray cone angle with elevated fuel temperature is already observable in these images. Similar findings in Figures 9 and 6 confirm that the macroscopic spray is strongly dominated by the fuel-dependent nozzle flow that is already visible in the microscopic spray shape at the nozzle exit.

From the single-shot images of the spray visualization, a geometric analysis of the microscopic spray quantities, spray width, spray cone angle and the bent 
Table 2. Fuel- and fuel temperature-dependent averaged spray quantities (with standard deviations in parentheses, indicating the temporal fluctuations) during needle opening $(200 \mu \mathrm{s})$ and quasi-stationary injection phase (500 $\mu \mathrm{s}$ after vSOI), Mie imaging.

\begin{tabular}{|c|c|c|c|c|c|}
\hline \multirow[t]{2}{*}{ Parameter (experiment) } & \multirow[t]{2}{*}{ Unit } & \multicolumn{2}{|l|}{ n-decane } & \multicolumn{2}{|l|}{ n-hexane } \\
\hline & & $25^{\circ} \mathrm{C}$ & $70^{\circ} \mathrm{C}$ & $25^{\circ} \mathrm{C}$ & $70^{\circ} \mathrm{C}$ \\
\hline Spray cone angle $(200 \mu \mathrm{s})$ & $\circ$ & $42.9(14.2)$ & $37.4(10.4)$ & $34.9(9.2)$ & $33.5(6.8)$ \\
\hline Bent angle $(200 \mu \mathrm{s})$ & $\circ$ & $6.8(5.2)$ & $6.4(4.0)$ & $8.6(4.6)$ & $8.8(3.7)$ \\
\hline Spray width $200 \mu \mathrm{s}$ ) & $\mathrm{mm}$ & $1.09(0.27)$ & $0.96(0.17)$ & $0.82(0.20)$ & $0.96(0.14)$ \\
\hline Spray cone angle $(500 \mu \mathrm{s})$ & $\circ$ & $34.5(8.9)$ & $32.2(8.3)$ & $34.0(4.5)$ & $28.8(4.5)$ \\
\hline Bent angle $(500 \mu \mathrm{s})$ & $\circ$ & $4.6(3.3)$ & $7.2(3.9)$ & $6.7(4.4)$ & $6.8(3.2)$ \\
\hline Spray width $(500 \mu \mathrm{s})$ & $\mathrm{mm}$ & $0.96(0.17)$ & $0.86(0.15)$ & $0.89(0.20)$ & $0.86(0.09)$ \\
\hline
\end{tabular}

Table 3. Fuel-dependent averaged flow quantities (with standard deviations in parentheses, indicating the temporal fluctuations) during partial needle lift.

\begin{tabular}{llll}
\hline Parameter (simulation) & Unit & & Partial needle lift $13 \mu \mathrm{m}$ \\
\cline { 4 - 4 } & & $\mathrm{n}$-decane $25^{\circ} \mathrm{C}$ & $\mathrm{n}$-hexane $25^{\circ} \mathrm{C}$ \\
\hline Axial velocity & $\mathrm{m} / \mathrm{s}$ & $63.7(3.0)$ & $73.7(2.7)$ \\
Radial velocity & $\mathrm{m} / \mathrm{s}$ & $0.05(1.36)$ & $0.81(1.80)$ \\
Non-axial energy $E_{k}$ & $J / \mathrm{kg}$ & $339(174)$ & $491(223)$ \\
Turbulent kinetic energy $T_{\mathrm{ke}}$ & $\mathrm{J} / \mathrm{kg}$ & $187(12)$ & $244(19)$ \\
Vapour volume fraction outlet & $\%$ & $8.59(2.90)$ & $10.90(3.00)$ \\
Vapour volume fraction total & $\%$ & $0.280(0.022)$ & $0.320(0.017)$ \\
\hline
\end{tabular}

Table 4. Averaged flow quantities (with standard deviations in parentheses) for full needle lift (URANS calculations).

\begin{tabular}{|c|c|c|c|c|c|}
\hline \multirow[t]{2}{*}{ Parameter (simulation) } & \multirow[t]{2}{*}{ Unit } & \multicolumn{2}{|l|}{ n-decane } & \multicolumn{2}{|l|}{ n-hexane } \\
\hline & & $25^{\circ} \mathrm{C}$ & $70^{\circ} \mathrm{C}$ & $25^{\circ} \mathrm{C}$ & $70^{\circ} \mathrm{C}$ \\
\hline Axial velocity & $\mathrm{m} / \mathrm{s}$ & $138.9(2.3)$ & | $44.3(2.0)$ & | $49.5(2.7)$ & I54.7 (2.1) \\
\hline Radial velocity & $\mathrm{m} / \mathrm{s}$ & $3.09(1.31)$ & $3.03(0.98)$ & 3.55 (I.22) & $3.55(1.18)$ \\
\hline Non-axial energy $E_{k}$ & $\mathrm{~J} / \mathrm{kg}$ & $1034(329)$ & $1074(265)$ & $1279(342)$ & 1426 (338) \\
\hline Turbulent kinetic energy $T_{\text {ke }}$ & $\mathrm{j} / \mathrm{kg}$ & $327(38)$ & $338(28)$ & $324(35)$ & $322(24)$ \\
\hline Vapour volume fraction outlet & $\%$ & $5.56(1.84)$ & $6.24(1.62)$ & $5.98(1.42)$ & $6.94(1.11)$ \\
\hline Vapour volume fraction total & $\%$ & $0.139(0.021)$ & $0.134(0.018)$ & $0.125(0.021)$ & $0.124(0.017)$ \\
\hline
\end{tabular}

angle of the single jet (i.e. the angle between the jet axis and the injection hole axis), can be performed, see Table 2 and Figure 10 for the definition of the spray quantities. The microscopic spray width is determined $1 \mathrm{~mm}$ below the nozzle orifice. The calculated jet bent angle represents the deviation of the injection direction from the injection hole axis. Per definition, the bent angle of the single jet is positive when it is directed towards the centreline of the injector. Thirty-two images of each time point were used for the calculations of average values and standard deviations ( $1 \sigma$ confidence level). During the needle opening phase (up to $200 \mu \mathrm{s}$, top rows of Table 2), the pressures rise in the injection hole and the spray is expanded. Accordingly, the spray cone angle as well as the spray width increases. For the full needle lift (e.g. at $500 \mu \mathrm{s}$, bottom rows of Table 2), the cone angle is reduced again due to the larger flow velocity and reduced cavitation, which will be discussed below (see Tables 3 and 4 and Figures 14 and 15). The cavitation is expected to

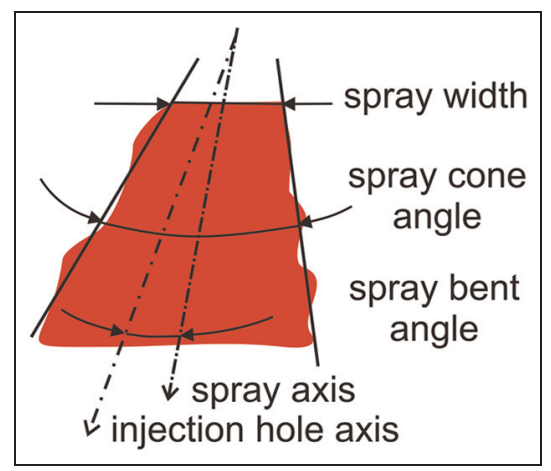

Figure 10. Schematic for the calculation of the microscopic spray quantities. The microscopic spray width was determined I $\mathrm{mm}$ below nozzle outlet. 


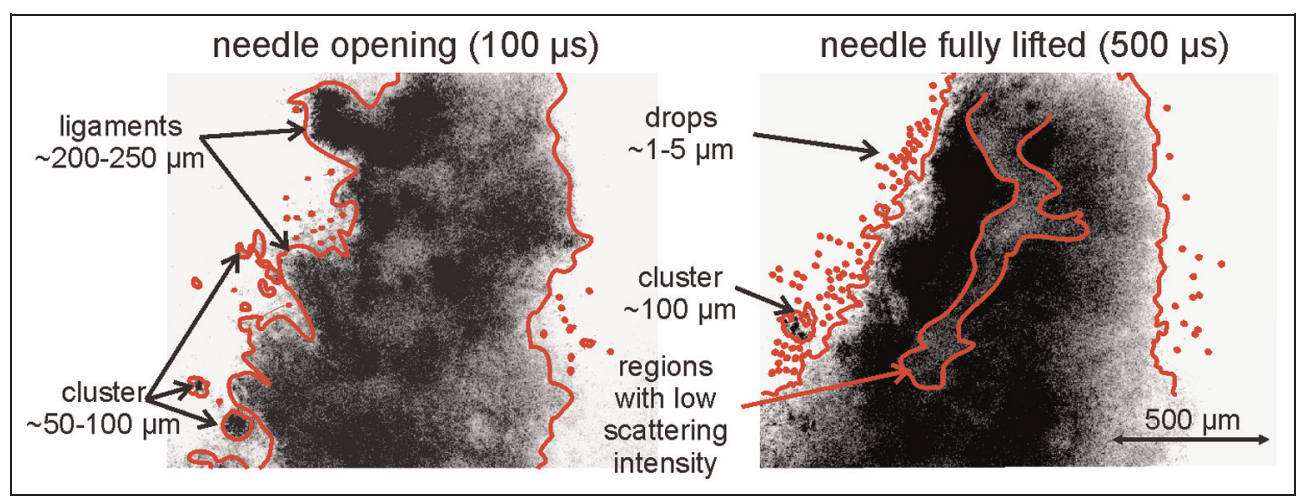

Figure II. Exemplary analysis of microscopic spray structures, n-decane, $\vartheta_{\text {Fuel }}=25^{\circ} \mathrm{C}$.

produce the largest contribution to the increase of the spray cone angle, which is also in accordance with the findings of Park et al. ${ }^{21}$ and Payri et al. ${ }^{32}$

$\mathrm{N}$-decane at $25^{\circ} \mathrm{C}$ (with the smallest Reynolds number) shows the largest average microscopic spray cone angle and the maximal standard deviations, whereas for n-hexane at $70{ }^{\circ} \mathrm{C}$, the smallest cone angle and standard deviations were calculated. For increased fuel temperature of $\mathrm{n}$-decane $\left(70^{\circ} \mathrm{C}\right)$, the cone angle is very similar to that one of $\mathrm{n}$-hexane at $25^{\circ} \mathrm{C}$; however, the fluctuations are still larger due to the smaller Reynolds number. Similar trends are noticeable for the bent angle and spray width, that is, for both fuels at increased temperature, the sprays turn slim and are bent further towards the injector centre axis. This spray bending and smaller averaged cone angle would lead to a larger spray penetration and a reduced macroscopic spray width, see Figure 6. In this flow regime, a Reynolds number dependency on the spray shape and cyclic variation could be demonstrated, while in the study by Sou et al., ${ }^{15}$ much larger Reynolds numbers (45,000-76,000, generic nozzle) were selected without significant effects on the sprays. However, further aspects must be considered that affect the flow field, such as scaling of the nozzles and the flow around the needle leading to vortex shedding and cavitation.

During needle opening (at $200 \mu \mathrm{s}$ ), the bent angle is larger; however, at the same time, the spray cone angle increases, which promotes jet-to-jet interactions, see Figure 5 . For the fully lifted needle $(500 \mu \mathrm{s})$, both spray cone angle and bent angle are decreased. The cyclic fluctuations are smaller, which is shown by the reduced standard deviations of the flow quantities when compared to its respective average values.

Another important aspect to be discussed is the spray structure and shape. The single-shot images in Figures 7 and 8 show the changed spray morphology of the different fuels during needle opening and full needle lift. In general, a relatively homogeneous scattering intensity occurs in the spray indicating a high amount of scatter centres in this region, which can be either single droplets and/or gas bubbles in the jet. For n-decane, an increased number of large surface perturbations is visible (Figure 7, e.g. images \#4 and \#5 at $200 \mu \mathrm{s}$ ), compared to n-hexane (Figure 8).

A structural analysis was performed to quantify the dimensions of the surface perturbations (such as ligaments or sheets, clusters, etc.), some examples are given in Figure 11. During the opening of the needle (100 $\mu \mathrm{s}$, left), the liquid spray is characterized by large surface perturbations as well as the formation of ligaments with typical dimensions of $100-200 \mu \mathrm{m}$ and clusters that are around 50-100 $\mu \mathrm{m}$. In Figure 12, a comparison of the dimensions of ligaments/sheets is provided for $n$ hexane and n-decane during the needle opening phase. The analysed time steps are 100, 125, 150 and $200 \mu \mathrm{s}$, and more than 4000 structures were verified for each fuel. The analysed structure dimensions were subdivided in intervals of $40 \mu \mathrm{m}$, whereas the range of 280 $320 \mu \mathrm{m}$ also contains few larger structures up to about $500 \mu \mathrm{m}$. For n-hexane, a reduced number of ligaments and clusters with dimensions between 160 and $320 \mu \mathrm{m}$ occur (about 30\% less compared to n-decane). The tendency towards smaller ligaments for $n$-hexane can be explained by the larger turbulence (Reynolds number) and the stronger cavitation, which is discussed in the CFD study below. During full needle lift (e.g. at $500 \mu \mathrm{s})$, the spray shape of both fuels shows less large

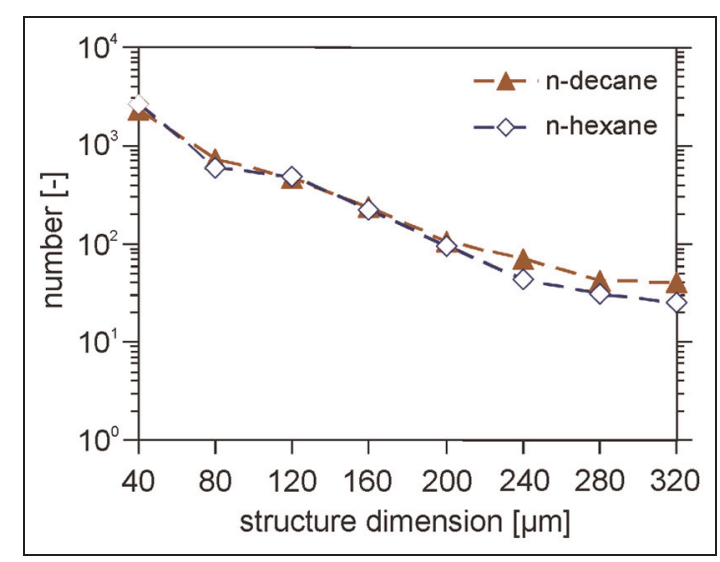

Figure 12. Comparison of microscopic spray structures (ligaments and clusters) during early injection phase (100$200 \mu \mathrm{s})$, n-decane and n-hexane, $\vartheta_{\text {Fuel }}=25^{\circ} \mathrm{C}$. 


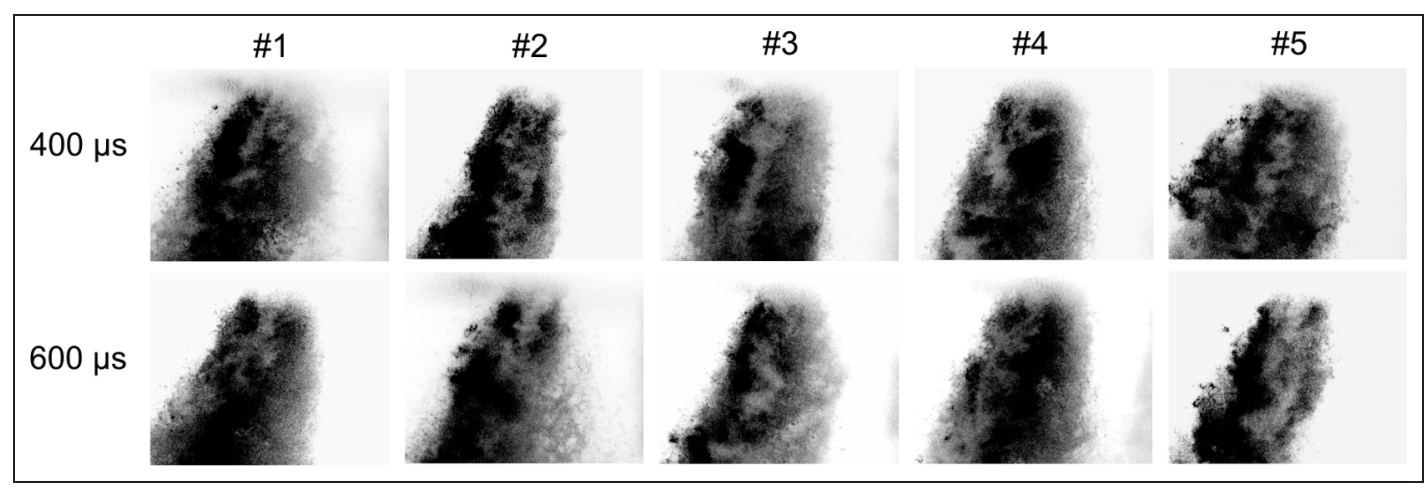

Figure 13. Microscopic spray images for n-decane at 400 and $600 \mu \mathrm{s}, \vartheta_{\text {Fuel }}=25^{\circ} \mathrm{C}$. The inner spray frequently shows large regions with low scattering intensity (in white/light-grey) especially occurring at the nozzle outlet.

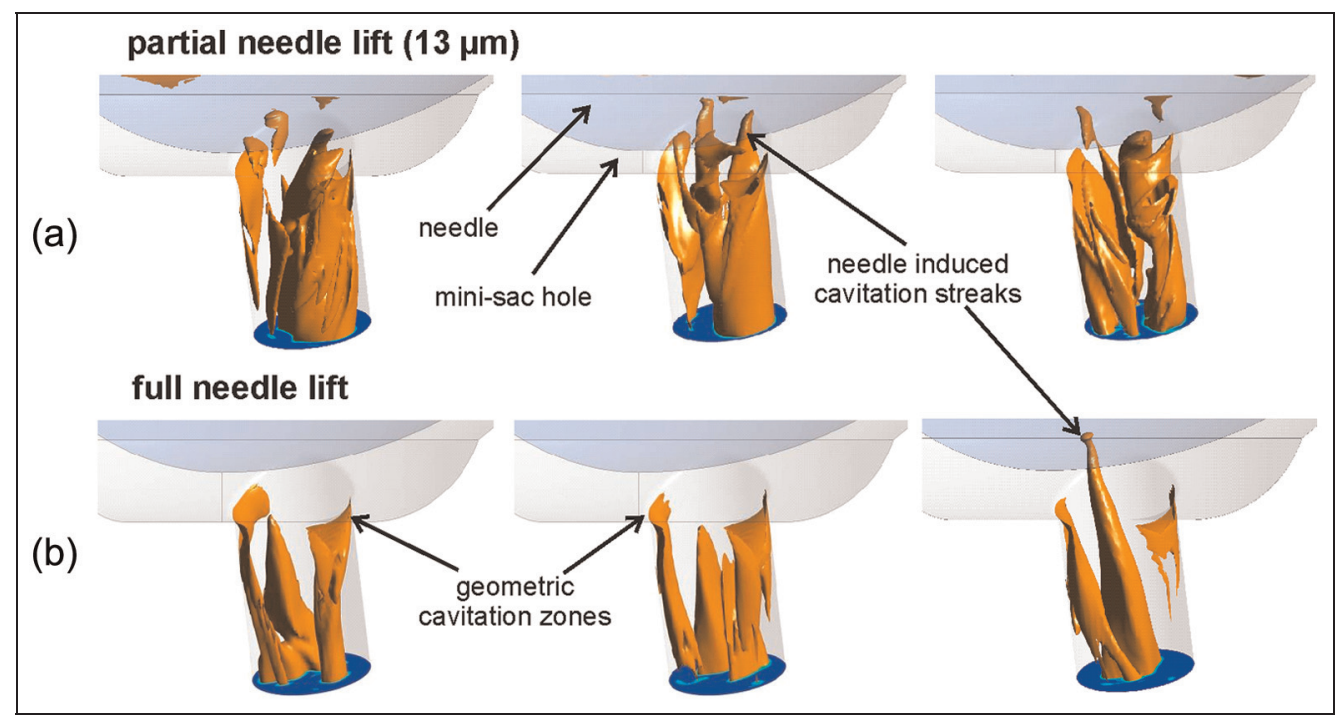

Figure 14. URANS simulation of the nozzle flow showing the cavitation behaviour of $n$-decane at three subsequent time steps (time interval is $40 \mu \mathrm{s}$ ), $50 \%$ vapour volume fraction, $\vartheta_{\text {Fuel }}=25^{\circ} \mathrm{C}$ for (a) partial and (b) full needle lift.

surface perturbations, see Figures 7 and 8; however, still cyclic variations can be detected, but they show reduced intensity. The spray structure of $n$-hexane appears more homogeneous and less chaotic.

Surprisingly, large-scale fractal structures with low scattering intensity are frequently visible inside the jet, see Figure 11 (right image). They occur in the spray during needle opening as well as in the quasi-stationary phase, see also Figure 13 (at 400 and $600 \mu$ s, n-decane). However, during full needle lift, their identification is easier since the spray is more homogeneous. The occurrence frequency of such structures in the quasistationary injection phase is about $30 \%$ of the images in a series. It has to be noted that most of those structures appear close to the nozzle orifice, but sometimes they are quite long-spread and also reach distances of 2 $\mathrm{mm}$ below the injector. Since there is a high scattering intensity around those fractal regions, local laser beam attenuation should not lead to such strong signal changes inside the jet. Probably, the low scattering intensity originates from hollow structures resulting from the disintegration of the jet, but this cannot be clarified in this study. Although the detection system's depth of sharpness range is limited $(80 \mu \mathrm{m})$, still multiple scattering is an issue and the disturbing stray light makes the optical access of the inner spray structures difficult. Therefore, further spray analyses also with enhanced optical techniques such as ballistic imaging $^{33,34}$ or X-ray techniques ${ }^{35}$ are necessary.

Finally, the turbulent, cavitating nozzle flow is characterized by a CFD simulation. A detailed description of the vortex structure of a comparable real-size DISI nozzle is given in the study by Shi et al. ${ }^{29}$ showing the vortex generation in the sac hole around the needle tip using a URANS as well as a scale-adaptive-simulation (SAS) approach.

The flow and cavitation behaviour in the nozzle strongly depend on the needle lift. Figure 14 shows the instant vapour distribution in the nozzle represented by iso-surfaces of the $50 \%$ fuel vapour volume fraction for partial (Figure 14(a), the needle stroke is $13 \mu \mathrm{m}$ ) and maximum needle lift (Figure 14(b)). Three subsequent 


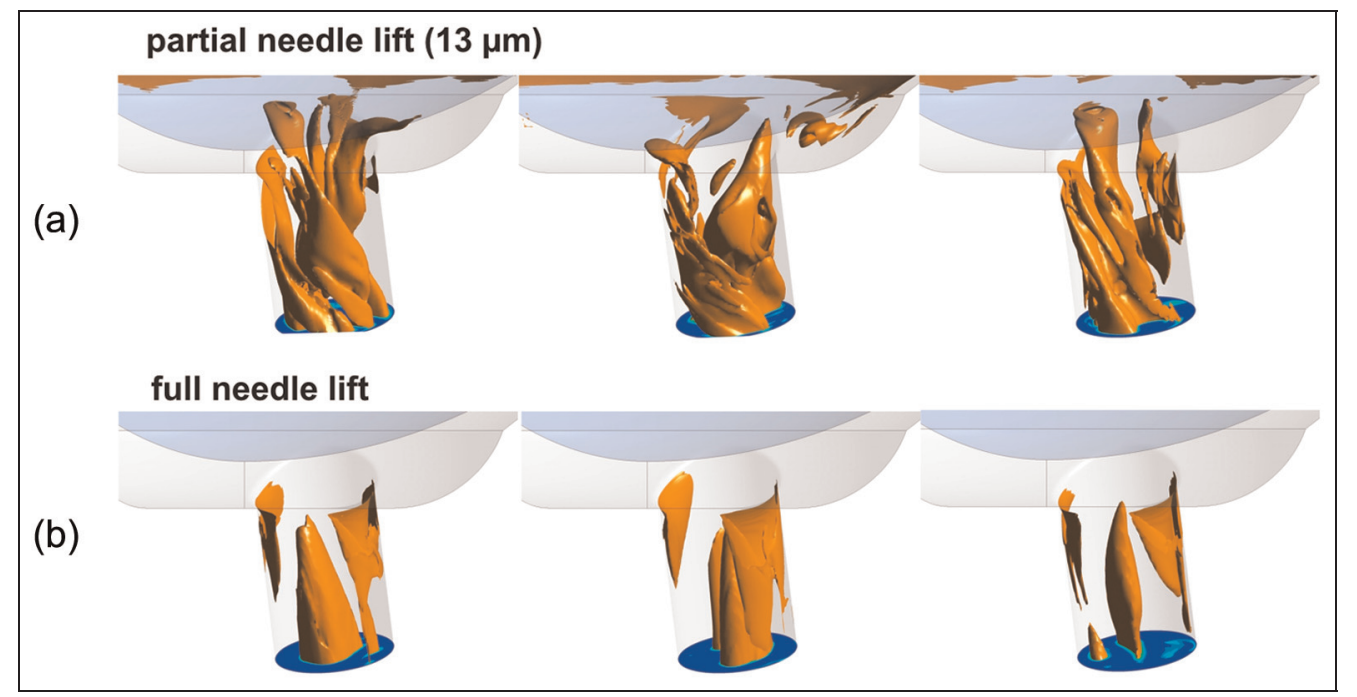

Figure 15. URANS simulation of the nozzle flow showing the cavitation behaviour of $n$-hexane at three subsequent time steps (time interval is $40 \mu \mathrm{s}$ ), $50 \%$ vapour iso-surface contours for (a) the partial needle lift and (b) full needle lift, $\vartheta_{\text {Fuel }}=25^{\circ} \mathrm{C}$.

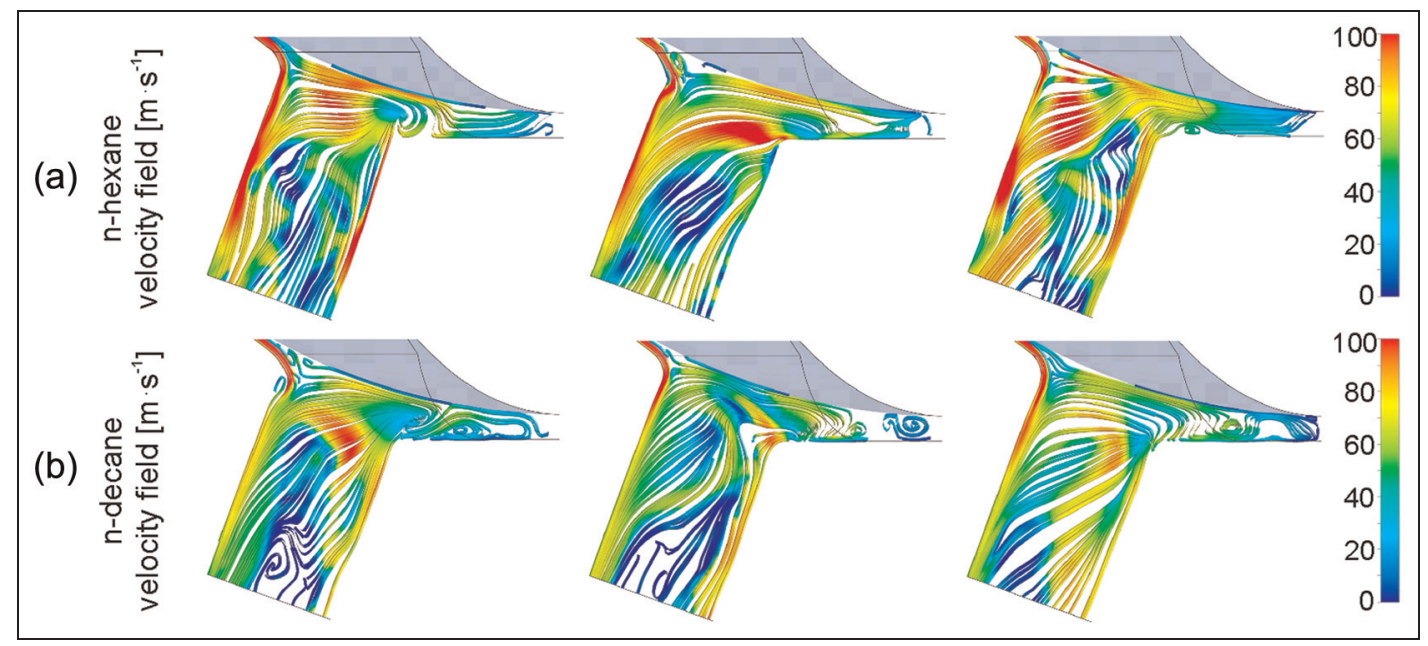

Figure 16. Surface streamlines coloured by velocity at the symmetry plane of one injection hole, $n$-hexane and $n$-decane, $13 \mu \mathrm{m}$ needle lift, $\vartheta_{\text {Fuel }}=25^{\circ} \mathrm{C}$.

time steps (time interval is $40 \mu \mathrm{s}$ ) are shown for n-decane at $10 \mathrm{MPa}$ and $25^{\circ} \mathrm{C}$. Much stronger cavitation was observed at the partial needle lift and large parts of the injection hole are filled with vapour. The unsteady ejection of cavitation vapour supports the temporal fluctuations in the nozzle flow and spray geometry. The vapour is primarily generated by geometric cavitation; however, single vortex- or needle-induced cavitation zones occur below the needle tip in the mini sac hole from time to time for both part and full needle stroke.

There are significant differences in the nozzle flow for n-decane and n-hexane leading to a changed cavitation behaviour that can be seen in Figures 14 (n-decane) and 15 (n-hexane). In Figure 16, the velocity profiles of the vapour distribution are presented for the same time steps as shown in Figures 14 and 15. During the partial needle lift, the shape of these large cavitation zones indicates a swirl motion of the flow inside the injection hole for n-hexane. Due to the increased flow velocity and turbulence in the sac hole and injection hole, the mixing of the liquid and vapour zones is enhanced for n-hexane compared to n-decane. Additionally, a reproducible swirl motion (Figure 15(a), partial needle lift) supports the jet stability showing reduced cyclic fluctuations for n-hexane. Furthermore, during the full needle lift, the cavitation zones show a less chaotic structure compared to n-decane, see Figure 14. The geometric cavitation zones are relatively large and reproducible. Less vapour streaks are formed at the needle tip, but some are visible in the injection hole.

The velocity field inside the nozzle hole and sac volume is represented by the streamlines in the symmetry plane for the partial needle lift and the two fuels at $25^{\circ} \mathrm{C}$ (Figure 16). The plot shows a highly unsteady 
and complicated flow that dominates the near-nozzle break-up mechanisms. Additionally, the flow velocity at the wall of the injection hole is much larger for nhexane (especially at the 'left' side of the wall). This may be an indication of the changed injection direction and bending of the spray to the injector axis and thus leads to a slimmer spray for n-hexane (see Figure 6). The maximum velocities are much lower for n-decane, and the velocity distribution shows a stronger flow deceleration at the walls that explains the larger spray cone angle.

In Tables 3 and 4, the average flow quantities (temporal and spatial averaged at outlet area) together with the corresponding standard deviations (in brackets) from CFD are given. The respective averaging time is $200 \mu \mathrm{s}$. The axial injection velocity is almost $14 \%$ smaller for n-decane compared to n-hexane at partial needle lift, see Table 3, which is consistent with the reduced penetration as shown in Figure 6. Interestingly, the average radial velocity during partial needle lift is very small for n-decane at $25^{\circ} \mathrm{C}(0.05 \mathrm{~m} / \mathrm{s})$ compared to its respective standard deviation $(1.36 \mathrm{~m} / \mathrm{s})$ also indicating the strong change of the flow direction and cyclic variations. The positive mathematical sign indicates the predominant flow directions towards the walls of the injection hole. However, no clear indication regarding the resulting spray cone angle is possible since the asymmetric flow field is too complex (see Figure 16) and also the injection direction is influenced (i.e. the spray bent angle).

Due to the strong swirl motion for n-hexane, also the non-axial energy is $30 \%$ larger, which is the main difference in the flow quantities of the certain fuels and is expected to dominate the spray atomization. In addition, the turbulent kinetic energy is about $23 \%$ increased. The $21 \%$ larger vapour volume fraction for n-hexane (at the outlet, $12.5 \%$ in the whole nozzle volume) implies a faster disintegration of the jet, which leads to less large surface perturbations compared to ndecane, see Figure 12. The higher axial velocity also promotes the aerodynamic break-up, which can be seen from the Weber numbers in Table 1. As shown in Figure 16(b), for n-decane, the large vortices in the nozzle flow might promote the formation of a broadened spray with stronger surface perturbations in the near field of the nozzle and, therefore, a larger spray cone angle as indicated in Table 2 .

For full needle lift, the axial velocity is doubled compared to the partial needle lift, see Table 4. At the same time, the turbulent kinetic energy is increased by a factor of two and the non-axial energy rises by a factor of three. Consequently, this should lead to a rapid atomization during the full needle lift and, thus, less large surface perturbations in the microscopic jet. Additionally, the standard deviations of the flow quantities are reduced in relation to the increased average value during the quasi-stationary injection phase (see Table 4), which is expected to damp the cyclic fluctuations in the spray shape (see Table 2). Furthermore, the reduced vapour amount due to cavitation at full needle lift supports the spray stability, which is also visible in the lowered cyclic fluctuations.

During the full needle lift, the differences in the turbulent flow field and vapour formation depending on the fuel and its temperature are smaller, see Table 4. This can also be confirmed by the measured spray cone angle and spray width, which are similar during the quasi-stationary injection phase $(500 \mu \mathrm{s}$, see Table 2) but still show the Reynolds number trend. One reason is that the needle-induced cavitation is reduced and the nozzle flow is similar for both fuels. For example, the turbulent kinetic energy and the vapour volume fraction converge for all tested operating conditions.

At elevated temperature, the axial velocities are further increased (about 3\%-4\%) due to the reduced fuel viscosity, which can lead to a larger momentum and spray penetration (Figure 6). The changed density (difference is about $4 \%-6 \%$ for increased temperature) is expected to play a minor role in atomization and spray propagation as it has a smaller impact on the spray momentum. A stabilized flow and reduced spray flipping result due to the larger flow velocities and enhanced mixing of the liquid and vapour. It is remarkable that the standard deviations of the flow quantities decline with increasing fuel temperatures in accordance with the cyclic spray variations, especially in the measured spray cone angle.

\section{Conclusion}

In this study, the fuel-dependent nozzle flow, atomization and macroscopic spray shape were examined for a three-hole DISI injector by a combined CFD and spray imaging approach. It could be shown that the geometric spray properties are mainly determined by the nozzle flow properties, especially the velocity profile and its flow stability. A correlation to the Reynolds number was found for the chosen injection conditions. Especially, for low Reynolds numbers in the transitional flow regime $(\mathrm{Re} \sim 9000)$, large cyclic variations in the calculated nozzle flow field and in the spray shape occurred. In general, the geometric and vortexinduced cavitation dominates the nozzle flow and atomization especially during injector opening and supports cyclic variations. At full needle lift, the cavitation is reduced, while the flow velocity is increased leading to smaller spray cone angles and reduced cyclic fluctuations in the nozzle flow field and in the spray.

When changing the fuel and its temperature, the dominant influence of the liquid fuel viscosity on the cavitating, turbulent nozzle flow, atomization and spray shape becomes apparent. A reduced viscosity (or increased Reynolds number) increases cavitation in the nozzle and also swirl and turbulence are generated leading to a slim microscopic spray with reduced spray width. The predicted larger axial flow velocity for lowviscosity fuels explains the increased spray length. For fuels with higher viscosity, the flow deceleration at the 
wall is larger, which explains the larger spray cone angle and the reduced spray penetration. Additionally, the increased bending of the jet towards the injector axis with larger Reynolds number could be predicted by the simulated flow field at the nozzle outlet. This fuel-dependent effect cannot be described by the aerodynamic break-up in the classical atomization theory, since the spray geometry is mainly influenced by the highly unsteady, cavitating nozzle flow and especially by the flow profile at those DISI injection conditions.

For n-hexane, smaller spray structures such as ligaments and clusters were detected compared to n-decane that is attributed to the stronger non-axial energy, cavitation and turbulent kinetic energy as predicted by the simulation. In the microscopic spray close to the nozzle outlet, frequently large fractal regions with low scattering intensity were detected, which could originate from hollow structures in the disintegrating jet. To clarify this, further investigations of such sprays are necessary.

Due to their highly complex influence on flow, turbulence and cavitation, the fuel properties need further investigation. In future work, the proper decoupling of the fuel properties, viscosity, vapour pressure, density and surface tension, by an appropriate selection of additional fuels will help to get a deeper insight into the flow and atomization process. Application of enhanced optical measurement techniques is expected to provide a deeper insight into the cavitating, turbulent nozzle flow and its effects on spray structures.

\section{Acknowledgements}

The authors thank Dr Eberhard Kull and Dr Milos Tichy (Continental Automotive GmbH, Regensburg) and Dr Jerome Helié (Continental Automotive SAS, Toulouse) for stimulating discussions within a fruitful collaboration during the last years and Dr Helie for providing the injector.

\section{Conflict of interest}

The authors declare that there are no conflicts of interest.

\section{Funding}

The authors gratefully acknowledge the financial support for parts of this work by the Erlangen Graduate School in Advanced Optical Technologies (SAOT), which is funded within the framework of the German Excellence Initiative by the German Research Foundation (DFG).

\section{References}

1. Zhao F-Q, Lai M-C and Harrington D-L. Automotive spark-ignited direct-injection gasoline engines. Prog Energ Combust 1999; 25: 437-562.

2. Zigan L, Schmitz I, Flügel A, et al. Effect of fuel properties on spray breakup and evaporation studied for a multi-hole direct injection spark ignition (DISI) injector. Energ Fuel 2010; 24: 4341-4350.

3. Zigan L, Flügel A, Schmitz I, et al. Structure of evaporating single- and multi-component fuel sprays for 2 nd generation gasoline direct injection. Fuel 2011; 90: 348-363.

4. Gavaises M, Tonini S, Marchi A, et al. Modelling of internal and near-nozzle flow of a pintle-type outwardsopening gasoline piezo-injector. Int J Engine Res 2006; 7(5): 381-397.

5. Lefebvre AH. Atomization and sprays. New York: Hemisphere Publishing Corporation, 1989.

6. Som S and Aggarwal SK. Effects of primary breakup modeling on spray and combustion characteristics of compression ignition engines. Combust Flame 2010; 157(6): 1179-1193.

7. Reitz RD. Modeling atomization processes in highpressure vaporizing sprays. Atomization Spray Technol 1987; 3: 309-337.

8. Jiang X, Siamas GA, Jagus K, et al. Physical modelling and advanced simulations of gas-liquid two-phase jet flows in atomization and sprays. Prog Energ Combust 2010; 36: 131-167.

9. Desjardins O, Blanquart G, Balarac G, et al. High order conservative finite difference scheme for variable density low Mach number turbulent flows. J Comput Phys 2008; 227: 7125-7159.

10. Huh KY and Gosman AD. Phenomenological model of diesel spray atomisation. In: Proceedings of the international conference on multiphase flows, Tsukuba, Japan, 24-27 September 1991, pp.515-518.

11. Baumgarten C. Mixture formation in internal combustion engines. Berlin: Springer, 2006.

12. Stiesch G. Modeling engine spray and combustion processes. Berlin: Springer, 2003.

13. Badock $\mathrm{C}$, Wirth $\mathrm{R}$, Fath $\mathrm{A}$, et al. Investigation of cavitation in real size diesel injection nozzles. Int $J$ Heat Fluid Fl 1999; 20: 538-544.

14. Arcoumanis C, Gavaises M and French B. Effect of fuel injection processes on the structure of diesel sprays. SAE paper 970799, 1997.

15. Sou A, Hosokawa S and Tomiyana A. Effects of cavitation in a nozzle on liquid jet atomization. Int $J$ Heat Mass Tran 2007; 50: 3575-3582.

16. Srinivasan V, Salazar AJ and Saito K. Modeling the disintegration of cavitating turbulent liquid jets using a novel VOF-CIMD approach. Chem Eng Sci 2010; 65: 2782-2796.

17. Lai MC, Zheng Y, Matsumoto A, et al. Characterisation of internal flow and spray of multihole DI gasoline spray using X-ray imaging and CFD. SAE technical paper series JSAE 20119225, SAE 2011-01-1881, 2011.

18. Andriotis A, Gavaises M and Arcoumanis C. Vortex flow and cavitation in diesel injector nozzles. $J$ Fluid Mech 2008; 610: 195-215.

19. Shi J-M and Arafin MS. CFD investigation of fuel property effect on cavitating flow in generic nozzle geometries. In: ILASS-Europe 2010, 23rd annual conference on liquid atomization and spray systems, Brno, Czech Republic, 6-8 September 2010. ILASS Europe.

20. Aleiferis PG, Serras-Pereira J, Augoye A, et al. Effect of fuel temperature on in-nozzle cavitation and spray formation of liquid hydrocarbons and alcohols from a real-size optical injector for direct-injection spark-ignition engines. Int J Heat Mass Tran 2010; 53: 4588-4606. 
21. Park SH, Suh HK and Lee CS. Effect of cavitating flow on the flow and fuel atomization characteristics of biodiesel and diesel fuels. Energ Fuel 2008; 22: 605-613.

22. Zigan L, Ammon M, Gupta V, et al. Investigation of fuel effects on spray atomization and evaporation studied for a multi-hole DISI injector with a late injection timing (SAE technical paper series 2011-01-1982). SAE Int J Fuels Lubr 2011; 5(1): 254-264.

23. Tanasawa $\mathrm{Y}$ and Toyoda S. On the atomization of liquid jet issuing from a cylindrical nose. Technical report. Report no. 19-2, 1955. Sendai, Japan: Tohoku University.

24. Bronkhorst ${ }^{\circledR}$ High-Tech. Fluidat on the net V1.18/5.70massflow and physical properties calculator, http:// www.fluidat.com

25. Dean JA. Lange's handbook of chemistry. New York: 15th ed., McGraw-Hill, Inc., 1999.

26. Fath A, Münch K-U and Leipertz A. Spray break-up of diesel fuel close to the nozzle. In: ILASS-Europe 1996, 12th annual conference on liquid atomization and spray systems, Lund, Sweden, 19-21 June 1996. ILASS Europe, pp.59-64.

27. Heimgärtner $C$ and Leipertz $A$. Investigation of the primary spray breakup close to the nozzle of a common rail high pressure diesel injection system. SAE technical paper series 2000-01-1799, 2000.

28. Schmitz I, Ipp W and Leipertz A. Microscopic investigations of primary gasoline spray breakup of a high-pressure swirl injector. In: 8th international conference on liquid atomization and spray systems (ICLASS), Pasadena, CA, 6-20 July 2000.

29. Shi J-M, Wenzlawski C, Helie J, et al. URANS \& SAS analysis of flow dynamics in a GDI nozzle. In: ILASSEurope 2010, 23rd annual conference on liquid atomization and spray systems, Brno, Czech Republic, 6-8 September 2010, ILASS Europe.

30. Langtry RB and Menter FR. Correlation-based transition modeling for unstructured parallelized computational fluid dynamics codes. AIAA J 2009; 47: 2894-2906.

31. Brennen EC. Cavitation and bubble dynamics. New York and Oxford: Oxford University Press, 1995.

32. Payri F, Bermúdez V, Payri R, et al. The influence of cavitation on the internal flow and the spray characteristics in diesel injection nozzles. Fuel 2004; 83: 419-431.

33. Paciaroni $M$ and Linne M. Single-shot, two-dimensional ballistic imaging through scattering media. Appl Optics 2004; 43: 5100-5109.

34. Idlahcen S, Méès L, Rozé C, et al. Time gate, optical layout, and wavelength effects on ballistic imaging. $J O p t$ Soc Am A 2009; 26: 1995-2004.

35. Wang Y, Liu X, Im K-S, et al. Ultrafast X-ray study of dense-liquid-jet flow dynamics using structure-tracking velocimetry. Nat Phys 2008; 4: 305-309. 